\title{
A quartz crystal biosensor for measurement in liquids
}

\section{Conrad KöBlingera, Stephan Drost ${ }^{\natural}$, Franz Aberl ${ }^{b}$, Hans Wolfb, Sabine Koch ${ }^{c} \&$ Peter Woias ${ }^{c}$}

\author{
${ }^{a}$ Fraunhofer-Institut für Festkörpertechnologie, Paul-Gerhardt-Allee 42, D-8000 München 60, Germany \\ ${ }^{b}$ Institut für Molekulare und Tumorvirologie am Max von Pettenkofer-Institut, Ludwig-Maximilians-Universität, \\ München, Germany \\ ${ }^{c}$ Lehrstuhl für Integrierte Schaltungen, Technische Universität München, Germany
}

(Received 17 May 1990; revised version received 3 October 1991; accepted 31 October 1991)

\begin{abstract}
The detection of anti-human immunodefficiency virus (HIV) antibodies by means of synthetic HIV peptide immobilized on a piezoelectric quartz sensor is demonstrated. The measurement set-up consists of an oscillator circuit, a suitably modified AT-cut thickness-shear-mode quartz crystal with gold electrodes, which is housed in a special reaction vessel, and a computercontrolled frequency counter for the registration of the measured frequency values. The quartz crystal is adapted for a steady operation in liquids at a frequency of $20 \mathrm{MHz}$. In phosphate-buffered saline solution the oscillator reaches a stability of about $0.5 \mathrm{~Hz}$ within a few seconds, of about $2 \mathrm{~Hz}$ within $10 \mathrm{~min}$ and about $30 \mathrm{~Hz}$ within $1 \mathrm{~h}$. The frequency shift due to the adsorption of various proteins to the uncoated sensor surface has been investigated. It can be shown that a stable adsorptive binding of proteins to an oscillating gold surface is feasible and can be used for the immobilization of a receptor layer (e.g. HIV peptide). Specific binding of the anti-HIV monoclonal antibody to the HIV peptide immobilized on the quartz sensor is demonstrated. Control experiments show, however, additional unspecific binding. According to the experiments, the Sauerbrey formula gives a sufficiently accurate value for the decrease of the resonant frequency due to adsorption or binding of macromolecular proteins on the quartz crystal surface.
\end{abstract}

Keywords: piezoelectric crystal, biosensor, immunosensor, anti-HIV antibody.

\section{INTRODUCTION}

The principle of microbalance can be used to detect minute amounts of biological or chemical substances via mass accumulation; this therefore represents a promising transducing mechanism for immuno-biosensors. It is also possible to observe binding reactions of proteins at surfaces in situ. This paper focuses on microbalances based on piezoelectric crystals, where a decrease of the resonant frequency can be correlated to accumulated mass.

An immunosensor that uses immobilized antigens for the detection of antibodies or vice versa can be applied in the following fields:

- clinical diagnostics (e.g. human immunodeficiency virus (HIV) test); 
- environmental control (e.g. detection of microorganisms in water);

- food industry (e.g. detection of toxic substances).

Compared to conventional measuring systems the advantages are short response times, the detection of the immunoreaction without additive reagents, and a direct conversion of mass accumulation into a frequency shift which represents an exactly measurable electrical signal.

Some recent publications show the possibility of direct immunosensing by bulk acoustic wave transducers (Davis \& Leary, 1989; Muramatsu et al., 1987, 1989; Thompson et al., 1986). In contrast to these experiments, this paper describes investigations of an experimental procedure without a flow-through cell and with an antigen/ antibody system which in the future might possess practical relevance for HIV research and HIV diagnostics.

The experiments demonstrate the effects of different protein-binding mechanisms to the oscillating sensor surface when measuring continuously in liquids.

The fundamental feasibility of an immunosensor based on a piezoelectric crystal is to be demonstrated. As a biological model system synthetic HIV peptide from the core shell of the HIV virus (p24) was used for the detection of the respective monoclonal antibody (Wolf et al., 1990; Modrow \& Wolf, 1990).

\section{MEASUREMENT SET-UP}

Figure 1 shows the measurement set-up, which was used for all experiments. The decisive difference from other measurement set-ups, described for example by Thompson et al. (1986), is the reaction vessel, which is not a flow-through cell. Thus the measurement procedure also differs from that described by Thompson et al (1986) or by Muramatsu et al. (1987).

The reaction vessel contains an AT-cut quartz, operating at $20 \mathrm{MHz}$. It was mounted at the bottom of the reaction vessel, exposing only one electrode to the sample solution. The reaction vessel was made of stainless steel. The electrodes consisted of gold-plated nickel and were fabricated by Quarzkeramik GmbH, Stockdorf, Germany. The electrical feedback loop was located very close to the sensor quartz. The resonant frequency of the oscillator was determined by a computercontrolled frequency counter and was additionally monitored with a chart-recorder.

In order to detect correlations between variations of temperature and changes of frequency, the temperature was measured by a temperaturedependent platinum resistor (PT 100). The resistance was measured by a computer-controlled ohmmeter.

The reaction vessel and the oscillator circuit were placed in a chamber to protect the measurement against thermal, mechanical and electrical influences.

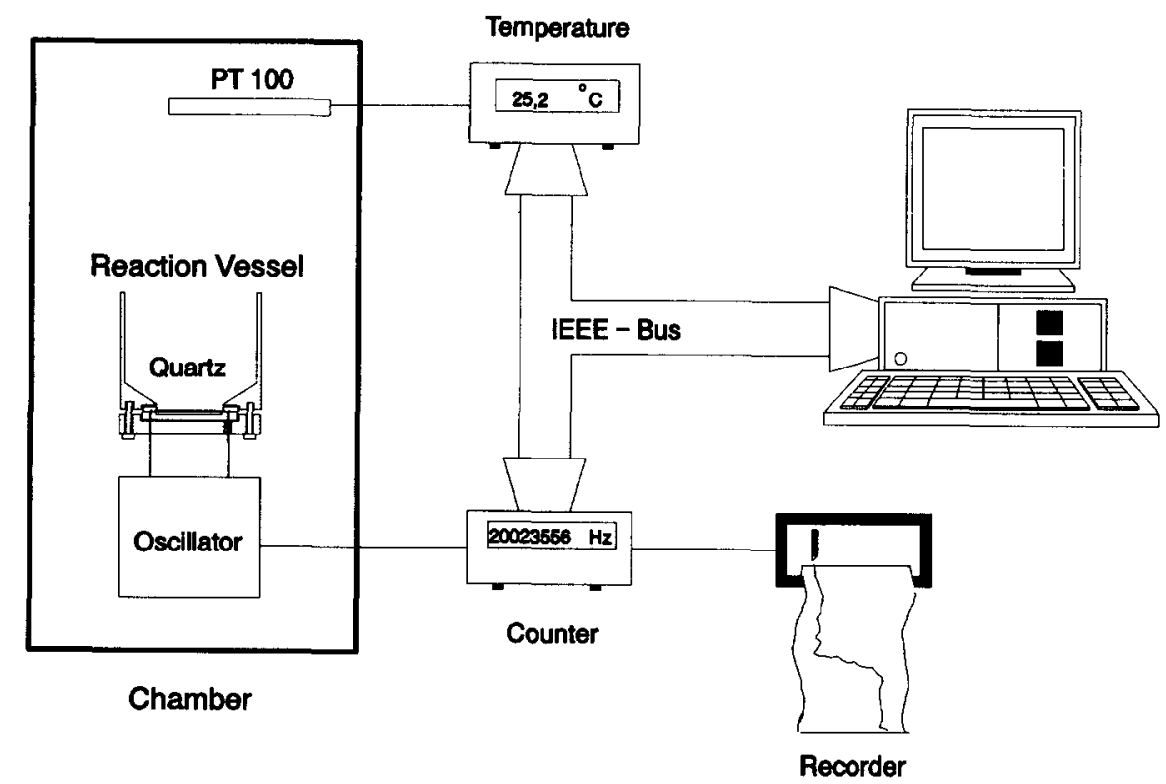

Fig. 1. Measurement set-up. 


\section{GENERAL FEATURES OF THE MEASUREMENT SYSTEM}

The following parameters are essential for the characterization of sensor performance: detection limits, response times and mass sensitivities (i.e. the frequency response due to the mass change at the quartz surface, or, more generally, due to changes of the gold/water interface conditions like viscosity, density and sound velocity of surface layer).

The most important theoretical considerations dealing with sensitivity were published by Sauerbrey (1959), Chi-shun Lu (1975), and Kanazawa \& Gordon (1985).

Kanazawa found the most extensive relation between change of frequency and viscoelastic properties at the surface of the quartz crystal. Lu considered the elastic properties of thick multilayers, whereas Sauerbrey's formula deals only with thin solid films on the quartz crystal surface. The greatest advantage of the Sauerbrey formula is that all parameters are easily accessible and the change of the resonant frequency only depends on the surface mass density (Sauerbrey, 1959):

$$
\Delta f=s \Delta m
$$

and

$$
S=-2 f^{2} / Z_{\mathrm{p}}
$$

where $\Delta f=$ frequency shift, $\Delta m=$ change of mass per area, $S=$ mass sensitivity, $Z_{\mathrm{p}}=$ acoustical impedance, and $f=$ resonant frequency.

With $Z_{\mathrm{p}}=8.85 \times 10^{14} \mathrm{ng} \mathrm{Hz} \mathrm{cm}{ }^{-2}$ and a resonant frequency of $20 \mathrm{MHz}$ the resulting sensitivity can be calculated as $S=0.904 \mathrm{~Hz}$ $\mathrm{ng}^{-1} \mathrm{~cm}^{2}$. In other words, a mass accumulation of $1 \mathrm{ng} \mathrm{cm}{ }^{-2}$ causes a frequency shift of about $1 \mathrm{~Hz}$.

However, this formula does not consider any viscoelastic effects, which might occur in liquids while binding reactions at the surface take place. Nevertheless, the Sauerbrey formula gives good values for estimations, as shown by the experiments described below. Viscoelastic effects do not play an important role for the performed experiments.

A short theoretical calculation for kinetics of immunochemistry at surfaces, which determines reaction times and frequency response times, was given by Thompson et al. (1987), who gives a solution of the Fick equation. There, a reaction time of $0.5 \mathrm{~s}$ for a coverage of $50 \%$ of the surface corresponds to an antibody concentration of $10^{-6} \mathrm{M}$. Lower antibody concentrations would cause lower rates of antigen/antibody formation. These calculations treat only boundary conditions which can be formalized. The procedure of carrying out experiments can be decisive for the response times. In this paper the resulting response times were in the range of a few minutes.

The detection limits depend on long-term stability, sensitivity, response time and the time that can be allowed for the measurement. Therefore no exact value for detection limits can be given. A value which is of some interest for detection limits is the minimum amount of mass at the quartz crystal surface, which causes a significant drop in frequency. For these considerations we assume a sensitivity of $1 \mathrm{~Hz} \mathrm{ng}^{-1} \mathrm{~cm}^{-2}$. The drop in frequency should be twice as much as the long-term fluctuations of frequency. These long-term fluctuations are likely caused by viscosity effects at the water-quartz interface, in contrast to the short time fluctuations, which are much smaller and caused by noise of the oscillator circuit. The used oscillator circuit with a $20 \mathrm{MHz}$ quartz reveals $\pm 0.5 \mathrm{~Hz}$ variation for observation intervals of $4 \mathrm{~s}$, which is the detection limit of the used counter. The long-term stability over $1 \mathrm{~h}$ is about $30 \mathrm{~Hz}$. With a required frequency drop of about $60 \mathrm{~Hz}$, the above assumed sensitivity and an electrode area of about $0.05 \mathrm{~cm}^{2}(2.5 \mathrm{~mm}$ diameter), a minimum amount of mass of about $3 \mathrm{ng}$ is needed. But this value is theoretical and it is not the subject of these experiments to reach this boundary.

Another important fact is the influence of temperature effects. Quartz crystals with exact AT-cut have very good temperature stability at room temperature in air or in a vacuum. The temperature profile worsens dramatically when the quality factor of the quartz crystal falls from 40000 in air to 5000 in water. This causes a temperature profile of $100 \mathrm{~Hz} \mathrm{~K}^{-1}$. However, parallel measurement of temperature and frequency in water showed negligible temperature fluctuations. Nevertheless the temperature dependence has to be improved for better longterm stability over hours and days.

\section{EXPERIMENTS}

The following preparatory procedure was used for all experiments. First the mounted quartz 
crystal was cleaned with hydrogen chloride (pH 3) and rinsed with chloroform. The reaction vessel was filled with $5 \mathrm{ml}$ of phosphate-buffered

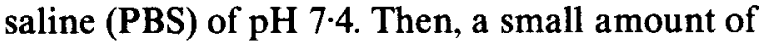
relatively highly concentrated sample solution was added. All experiments were performed without stirring. Rinsing was only used after the immobilization of the antigens. Owing to these procedures and the shape of the reaction vessel, we expected, after adding the sample solution, an inhomogenous distribution of proteins with a much higher concentration at the quartz electrode, which also should cause fast response times. These higher concentrations at the gold electrode were obviously caused by sedimentation. On the other hand, it was also expected that unspecific binding reactions should be promoted by this procedure. Furthermore, it was supposed that after reaching equilibrium the surface was nearly saturated. This was proved by the fact that further addition of proteins did not decrease the resonant frequency any more. Although boundary conditions were not defined as clearly as in a flow-through cell, the experiments showed positive results beyond doubt.

Each quartz crystal was used once to obtain the same starting conditions. Experiments to regenerate the immunosorbent surfaces have not been carried out owing to the aim of getting a disposable sensor for fast tests. Such a sensor can be used, for instance, in clinical tests as an alternative method to indirect immunological tests like ELISA.

The curves shown in Figs 2-5 are single measurements representing typical coarses of each type of measurement. The noise was smoothed out. Table 1 compares the measured values for the adsorption of proteins with the calculated data from the Sauerbrey equation. The surface particle density is given assuming a cubeshaped protein and a maximum package density. The frequency shift data are a summary of experiments using five different quartz crystals for every class of experiment, represented by a row in Table 1. The value of the frequency shift for a single measurement was rounded to $50 \mathrm{~Hz}$

TABLE 1 Comparison between measured and expected frequency shift due to reaction of proteins with the surface on condition of maximum packed surface layer

\begin{tabular}{|c|c|c|c|c|c|c|c|}
\hline Substance & $\begin{array}{l}\text { Mol. wt } \\
\left(\times 10^{3}\right)\end{array}$ & $\begin{array}{l}\text { Surface particle } \\
\text { density } \\
\left(\mathrm{cm}^{-2}\right)\end{array}$ & $\begin{array}{l}\text { Surface mass } \\
\text { density } \\
\left(\mathrm{g} \mathrm{cm}^{-2}\right)\end{array}$ & $\begin{array}{l}\text { Expected shift } \\
\text { of frequency } \\
(\mathrm{Hz})\end{array}$ & $\begin{array}{l}\text { Measured shift of } \\
\text { frequency (mean } \\
\text { value in } \mathrm{Hz} \text { ) }\end{array}$ & $\begin{array}{l}\text { Standard } \\
\text { deviation } \\
(\mathrm{Hz})\end{array}$ & $\begin{array}{l}\text { RDS } \\
(\%)\end{array}$ \\
\hline BSA & 65 & $7.0 \times 10^{12}$ & $7.7 \times 10^{-7}$ & 770 & 340 & 65 & 19 \\
\hline $\begin{array}{l}\text { Anti-HIV } \\
\text { peptide } \\
\text { antibody }\end{array}$ & 150 & $4.0 \times 10^{12}$ & $1.0 \times 10^{-6}$ & 1000 & 890 & 178 & 20 \\
\hline $\begin{array}{l}\text { Anti-EBV } \\
\text { antibody }\end{array}$ & 150 & $4.0 \times 10^{12}$ & $1.0 \times 10^{-6}$ & 1000 & 920 & 172 & 19 \\
\hline $\begin{array}{l}\text { Enzyme- } \\
\text { labelled } \\
\text { antibody }\end{array}$ & 600 & $1.6 \times 10^{12}$ & $1.6 \times 10^{-6}$ & 1600 & 1560 & 318 & 20 \\
\hline $\begin{array}{l}\text { Specific } \\
\text { reaction of } \\
\text { anti-HIV } \\
\text { peptide } \\
\text { antibody with } \\
\text { HIV antigens }\end{array}$ & 150 & $4.0 \times 10^{12}$ & $1.0 \times 10^{-6}$ & 1000 & 1000 & 146 & 15 \\
\hline $\begin{array}{l}\text { Unspecific } \\
\text { reaction of } \\
\text { anti-EBV } \\
\text { antibody with } \\
\text { HIV antigens }\end{array}$ & 150 & 0 & 0 & 0 & 320 & 152 & 48 \\
\hline
\end{tabular}


because of noise. Standard deviation and relative standard deviation (RSD) were also calculated.

\section{Adsorptive binding of different proteins}

Figure 2 shows the measured frequency shift due to adsorbed bovine serum albumin (BSA). In the first step (indicated by arrow 1) $20 \mu 1$ of BSA with a concentration of $1 \mathrm{mg} \mathrm{ml}^{-1}$ was added to a sample volume of $5 \mathrm{ml}$ PBS ( $\mathrm{pH} \mathrm{7.4).} \mathrm{In} \mathrm{the}$ second step (indicated by arrow 2) the same amount BSA was added again after $2 \mathrm{~min}$, before equilibrium was reached. The quartz was previously cleaned with hydrogen chloride $(\mathrm{pH} 3)$ and rinsed with chloroform.

The reaction velocity was increased significantly by doubling BSA concentration. The saturation value for the frequency shift in this measurement was about $350 \mathrm{~Hz}$ for a total amount of $20 \mu \mathrm{g}$ BSA in $5 \mathrm{ml}$ PBS and was reached after $6 \mathrm{~min}$.

Figure 3 gives a plot of the adsorption curves for various proteins, such as BSA (1), antibodies (2) and antibodies labelled with urease (3). The figure combines three separate measurements. The three curves were drawn shifted to each other for clarity. The amounts of protein added to $5 \mathrm{ml}$ PBS were: for BSA $20 \mu 1$ of a concentration of $1 \mathrm{mg} \mathrm{ml}^{-1}$; for the antibodies, $5 \mu 1$ of a concentration of $1 \mathrm{mg} \mathrm{ml}^{-1}$; and for the enzyme-labelled antibodies, $5 \mu \mathrm{l}$ of a concentration of $1 \mathrm{mg} \mathrm{ml}^{-1}$.

Curve 2 represents a set of measurements with

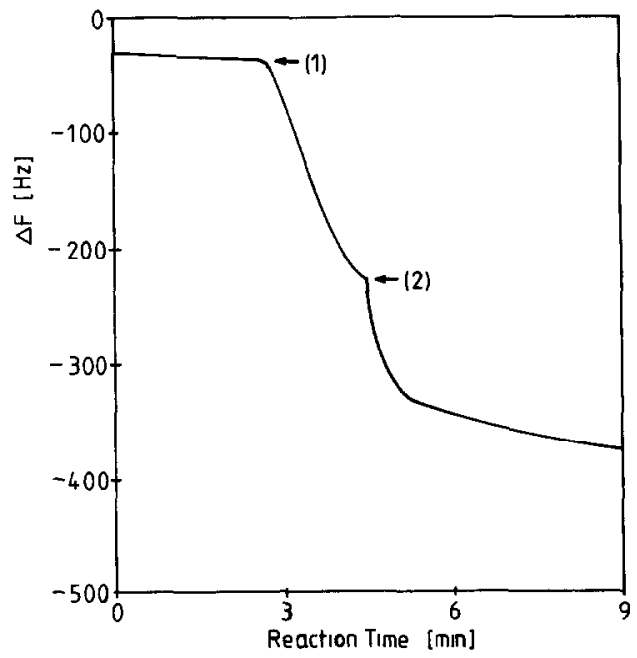

Fig. 2. Adsorption of BSA at the gold electrode. Five microlitres of BSA at a concentration of $10 \mu \mathrm{g} \mathrm{ml}^{-1}$ were added twice to a sample volume of $5 \mathrm{ml} \mathrm{PBS}$ (indicated by the two arrows).

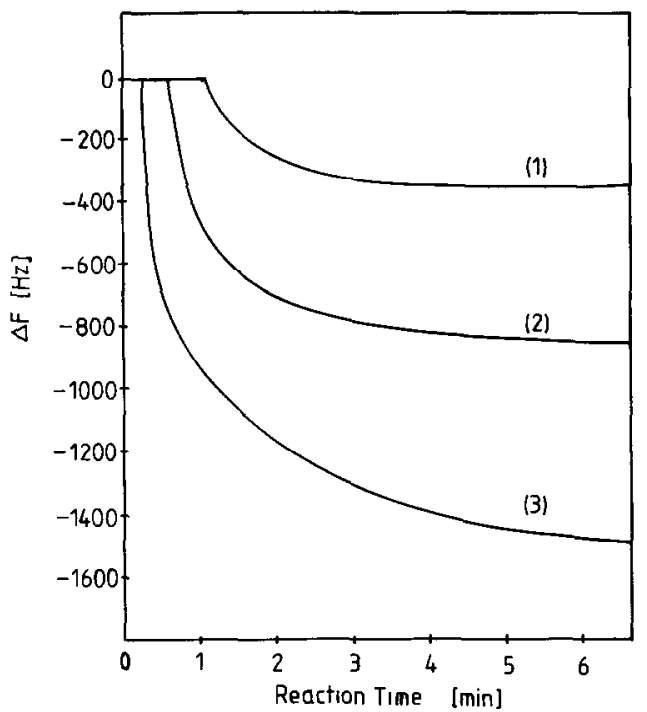

Fig. 3. Frequency response for adsorption at gold electrodes of BSA (1), antibodies (2) and enzyme-labelled antibodies (3). The figure combines three separate measurements. The three curves were drawn shifted to each other for more clarity. The amount of protein added to $5 \mathrm{ml} P B S$ were: for $B S A 20 \mu l$ of a concentration of $1 \mathrm{mg} \mathrm{ml}^{-1}$; for the antibodies, $5 \mu \mathrm{l}$ of a concentration of $1 \mathrm{mg} \mathrm{ml}^{-1}$; for the enzyme-labelled antibodies, $5 \mu \mathrm{l}$ of a concentration of $l m g m l^{-1}$.

two types of antibodies which show the same behaviour for adsorption at the gold electrode. The two antibody types were monoclonal antibodies purified by ammonium sulphate precipitation and specific to:

a synthetically produced peptide of the core shell of the HIV virus (Wolf et al., 1990; Modrow \& Wolf, 1990);

- the Epstein-Barr virus (EBV).

The precipitates were not further purified. The enzyme-labelled antibody was an FC antibody, specific to the FC part of antibodies. According to higher-frequency drops, this FC antibody was labelled by urease.

Comparison between calculated and measured values in Table 1 shows generally the same tendency but the standard deviation is relatively high. The RSD is about $20 \%$. The high RSD is probably caused by insufficiently reproducible experimental conditions. The measured data are below the expected maximum values.

As these measurements show a very stable binding of proteins to the electrode surface by mere adsorption, for further experiments an adsorptive immobilization of the antigen was 
chosen. The effectivity of this immobilization was controlled with ELISA and found to be sufficiently high.

\section{Binding of anti-HIV peptide antibody to adsorbed HIV peptide}

The adsorptive immobilization of HIV peptide was performed according to the following procedure:

(1) Cleaning of the gold electrode with chloroform.

(2) Dissolving the peptide in phosphate buffer (pH 7, 0.05 $\mathrm{M}$ ) at a concentration of $10 \mu \mathrm{g} \mathrm{ml}^{-1}$.

(3) Fifty microlitres of the above solution onto the quartz dropping; reaction allowed for $18 \mathrm{~h}$ at a temperature of $37^{\circ} \mathrm{C}$.

(4) Rinse with PBS-Tween.

After immobilization of the peptide remaining unspecific binding sites were saturated with gelatine and once again the sensor was rinsed with PBS. For the measurement the reaction vessel (see Fig. 1) was filled with $5 \mathrm{ml}$ PBS and $5 \mu 1$ of anti-HIV antibody were added, corresponding to a dilution of 1:1000. For these preliminary measurements a precipitate of monoclonal antibodies was used, which contained about $1 \mathrm{mg} \mathrm{ml}^{-1}$ antibody. An exact value cannot be given, as the precipitate was not purified by affinity chromatography.

Figure 4 shows the response of the piezoelectric sensor to the addition of anti-HIV antibody (indicated by an arrow). The saturation value of the frequency shift $(1000 \mathrm{~Hz})$ is reached after about $20 \mathrm{~min}$.

A control measurement, where first $5 \mu 1$ antiEBV antibody at a concentration of about $1 \mathrm{mg} \mathrm{ml}^{-1}$ were added, shows a frequency drop of about $300 \mathrm{~Hz}$ (Fig. 5), which probably results from unspecific (adsorptive) binding sites still remaining. The theoretical value for unspecific binding in Table 1 is zero.

After adding specific antibodies (again $5 \mu 1$ at a concentration of about $1 \mathrm{mg} \mathrm{m}^{-1}$ ) a frequency shift of about $800 \mathrm{~Hz}$ could be measured (time constant about $35 \mathrm{~min}$ ). A comparison of these measurements shows that the contribution of unspecific adsorption to the measured signal of Fig. 4 still remains, but is far below the total frequency shift. Nevertheless these preliminary results show clearly that a direct monitoring of antigen-antibody binding in liquids is feasible.

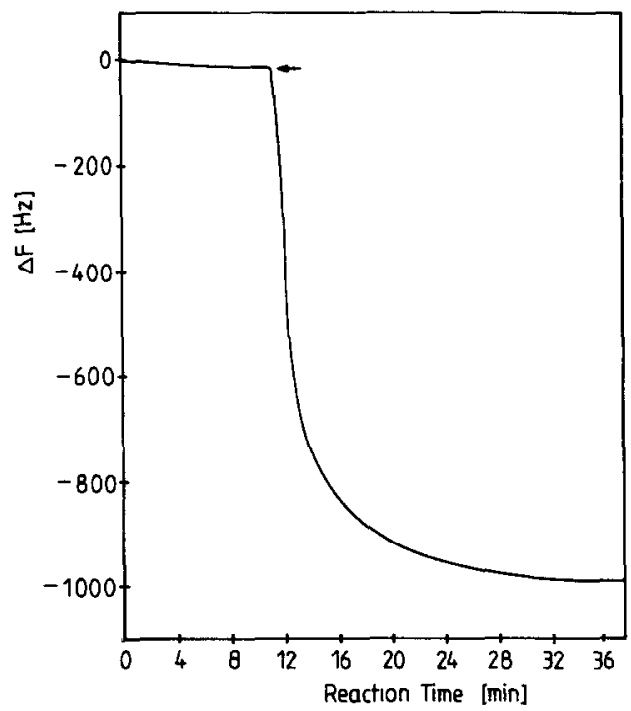

Fig. 4. Response for the reaction of anti-HIV antibody (dilution 1:1000) with adsorbed HIV peptide.

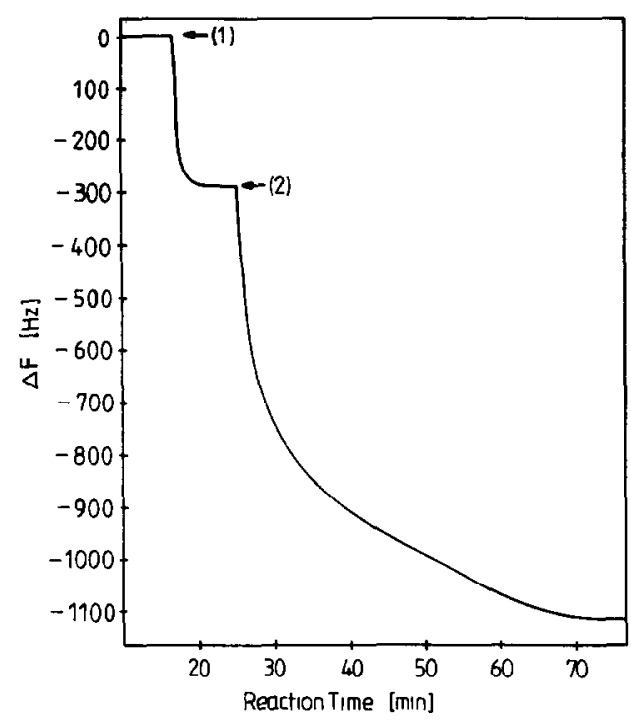

Fig. 5. Response for the unspecific adsorption of anti-EBV antibody to HIV peptide covered quartz (1) and the specific reaction of anti-HIV antibody (2).

\section{DISCUSSION AND CONCLUSIONS}

Using the measurement system described the piezoelectric crystal can be operated continuously in liquids at a frequency of $20 \mathrm{MHz}$.

The advantage of the demonstrated method of performing the experiments is the comparatively simple measurement set-up without pumps and valves for the flow-through cell. This also means much greater sample volumes compared to those 
in flow-through cells. The experiments show the potential suitability of this measurement system as an analytical method for the observation of binding reactions in situ. Furthermore, they provide the basic tools for an immunosensor for the detection of anti-HIV antibodies in human serum.

Table 1 summarizes the results of the experiments, which show that adsorbed proteins form a stable binding to the gold surface of the oscillating quartz electrode. Thus the immobilization of a receptor layer (here antigen) can be performed by mere adsorption and, provided that the molecular weight of the receptor molecule is high enough, the efficiency of immobilization can be controlled by the sensor itself. The high standard deviation of the measurements indicates a poor reproducibility of the adsorption conditions. This means improvement of the sensor surface treatment is essential.

The specific binding of monoclonal antibodies to adsorbed HIV peptides could be monitored online. According to control experiments, however, an additional effect which amounts to about one third of the reaction is produced by unspecific binding. Therefore the saturation of unspecific binding sites after coating the quartz with HIV peptide has to be optimized and, in addition, the measurement has to be performed in a differential mode with two piezoelectric sensors. This differential set-up should also reduce the influence of temperature variations on the frequency shift.

The comparison of the measured data with the calculated data show that the Sauerbrey formula provides sufficient accuracy for estimations. However, more knowledge of the viscoelastic properties of bound protein monolayers would be helpful for more accurate calculations and for a deeper comprehension of interface and surface effects.

The surface properties and therefore the preparation of the surfaces are of decisive importance for the response values, the response times and the sensitivity. The experimental boundary conditions can be controlled more precisely when using a flow-through cell, a stirred solution and additional washing steps, with an optimized saturation of unspecific binding sites and with a differential measurement method.

The described method of carrying out experiments, however, possibly provides a simple disposable measurement system for a fast and easy control of blood serum. This kind of appli- cation does not have as strict demands concerning reversibility as well as long-term stability of resonant frequency and sensor coating as applications in fermentation control in bioreactors or in environmental observation. On the other hand, the costs of disposable sensor systems have to be low, which is also an argument for the relatively cheap quartz crystals.

\section{ACKNOWLEDGEMENTS}

The authors wish to thank the following: $\mathrm{Dr}$ Susanne Modrow for the preparation of HIV peptides (Max von Pettenkofer-Institut, München); Norbert Schertler, Michael Engelbrecht and Markus Tristl (IFT) for measurements and electronics; Elke Drath (IFT) for drawings; and BMFT for financial support.

\section{REFERENCES}

Chi-shun Lu (1975). Mass determination with piezoelectric quartz crystal resonators. J. Vac. Sci. Technol., 12, 578-83.

Davis, K. A. \& Leary, T. R. (1989). Continuous liquidphase piezoelectric biosensor for kinetic immunoassays. Anal. Chem., 61, 1227-30.

Kanazawa, K. K. \& Gordon, J. G. (1985). The oscillation frequency of a quartz resonator in contact with a liquid. Anal. Chim. Acta, 175, 99-106.

Modrow, S. \& Wolf, H. (1990). Use of synthetic peptides as diagnostic reagents in virology. Immunochemistry of Viruses II, ed. Regenmortel et al. Elsevier, Amsterdam, 83-101.

Muramatsu, H., Dicks, J. M., Tamiya, E. \& Karube, I. (1987). Piezoelectric crystal biosensor modified with protein A for determination of immunoglobulins. Anal. Chem., 59, 2760-3.

Muramatsu, H., Tamiya, E. \& Karube, I. (1989). Determination of microbes and immunoglobulins using a piezoelectric biosensor. J. Membrane Sci., 41, 281-90.

Sauerbrey, G. (1959). Verwendung von Schwingquarzen zur Wägung dünner Schichten und zur Mikrowägung. Z. Phys., 155, 206.

Thompson, M., Arthur, C. L. \& Dhaliwal, G. K. (1986). Liquid-phase piezoelectric and acoustic transmission studies of interfacial immunochemistry. Anal. Chem., 58, 1206-9.

Thompson, M., Dhaliwal, G. K, Arthur, C. L. \& Calabrese, G. S. (1987). The potential of the bulk acoustic wave device as a liquid-phase immuno- 
sensor. IEEE Trans. Ultrasonics, Ferroelectrics and Frequency Control, UFFC-34, 127-35.

Wolf, H., Modrow, S., Soutschek, E., Motz, M., Grunow, R, Döbl, H. \& Baehr, R. von (1990). Herstellung,
Kartierung und biologische Charakterisierung von monoklonalen Antikörpern gegen das Core Protein (p24) des Humanen Immundefizienzvirus. AIDS-Forschung, 1, 16-18. 